University at Albany, State University of New York

Scholars Archive

Psychology Faculty Scholarship

Psychology

2010

\title{
Understanding Alcohol-Related Sexual Assaults: Characteristics and Consequences
}

Sarah E. Ullman

The University of Illinois at Chicago

Cynthia J. Najdowski

University at Albany, State University of New York, cnajdowski@albany.edu

The University at Albany community has made this article openly available.

Please share how this access benefits you.

Follow this and additional works at: https://scholarsarchive.library.albany.edu/psychology_fac_scholar

Part of the Clinical Psychology Commons, Counseling Commons, Counseling Psychology Commons, Criminology and Criminal Justice Commons, Domestic and Intimate Partner Violence Commons, Gender and Sexuality Commons, and the Social Psychology Commons

\section{Recommended Citation}

Ullman, Sarah E. and Najdowski, Cynthia J., "Understanding Alcohol-Related Sexual Assaults: Characteristics and Consequences" (2010). Psychology Faculty Scholarship. 29.

https://scholarsarchive.library.albany.edu/psychology_fac_scholar/29

This Article is brought to you for free and open access by the Psychology at Scholars Archive. It has been accepted for inclusion in Psychology Faculty Scholarship by an authorized administrator of Scholars Archive.

Please see Terms of Use. For more information, please contact scholarsarchive@albany.edu. 
Running head: UNDERSTANDING ALCOHOL-RELATED SEXUAL ASSAULTS

Revised version for $\mathrm{V} \& \mathrm{~V}$ - 2/22/09

PRE-PRINT. This paper is not the copy of record and may not exactly replicate the authoritative document published in the journal.

Understanding Alcohol-Related Sexual Assaults:

Characteristics and Consequences

Sarah E. Ullman

Cynthia J. Najdowski

University of Illinois at Chicago

Note:

Sarah E. Ullman, Ph.D.

Professor

Department of Criminology, Law, \& Justice University of Illinois at Chicago 1007 West Harrison Street, M/C 141

Chicago, IL 60607

seullman@uic.edu
Cynthia J. Najdowski, B.A.

Graduate Student

Department of Psychology

University of Illinois at Chicago

1007 West Harrison Street, M/C 285

Chicago, IL 60607

cnajdo2@uic.edu

This research was supported by a grant from NIAAA \#13455 to Sarah E. Ullman. We acknowledge Henrietta Filipas, Stephanie Townsend, Laura Starzynski, and Kelly Kinnison for 
assistance with data collection. An earlier version of this paper was presented at the 2008 Research Society on Alcoholism Meeting in Washington, DC. 


\begin{abstract}
Sexual assaults commonly involve alcohol use, but little is known about alcohol's effects on many aspects of assaults and their aftermath. We investigated characteristics of victims, perpetrators, and assaults as a function of whether alcohol was involved in the assault, as well as differences in women's post-assault experiences. Assaults prior to which only perpetrators were drinking differed not only from non-alcohol-related assaults, but also from those prior to which both perpetrators and victims were drinking. Understanding the effects of alcohol-related assaults is important for identifying victims who should be targeted for mental health and substance use interventions.
\end{abstract}

Key words: sexual assault, rape, alcohol 


\section{Understanding Alcohol-Related Sexual Assaults:}

\section{Characteristics and Consequences}

Approximately half of sexual assault cases involve drinking by the victim, perpetrator, or both prior to the assault (for reviews, see Abbey, Zawacki, Buck, Clinton, \& McAuslan, 2001; Ullman, 2003). In fact, research has shown that women who drink, particularly those who engage in heavy or binge drinking, are at higher risk for experiencing sexual assault compared to other women (for review, see Testa \& Livingston, in press). Yet little research has examined factors that determine which women are at increased risk of experiencing alcohol-related sexual assaults, or how characteristics and outcomes of alcohol-related assaults differ from other assaults, particularly in non-college samples of victims. Thus, we examined differences in preassault drinking patterns across (a) victim, perpetrator, and assault characteristics and (b) victims' responses to the assault.

\section{Victim, Perpetrator, and Assault Characteristics}

There are a variety of victim and perpetrator characteristics that might relate to whether an assault involves alcohol use by either party. For example, because having a history of child sexual abuse (CSA) is associated with an increased risk of both sexual assault and substance use (Acierno, Resnick, Kilpatrick, Saunders, \& Best, 1999; Wilsnack, Wilsnack, Kristjanson, Vogeltanz-Holm, \& Harris, 2004), it has been proposed that women's trauma histories may affect their likelihood of drinking prior to an assault. This is consistent with some research suggesting that victims of previous traumas are more likely than other women to use alcohol to cope with distress (Ullman, Filipas, Townsend, \& Starzynski, 2005) and, more specifically, that women with victimization histories are at greater risk for using substances during sexual activity (Randolph \& Mosack, 2006). Thus, women with trauma histories may be at increased risk of 
experiencing alcohol-related assaults due to exposure to risky settings where drinking occurs (e.g., bars, parties) and/or alcohol-related impairment. Littleton, Grills-Taquechel, and Axsom (in press) found no differences in terms of having a history of CSA in sexual assault victims from a college sample who were not drinking or using drugs prior to their assault compared to victims who were either impaired or intoxicated. However, they considered CSA history only in relation to whether the victim was drinking, not the perpetrator, and compared alcohol's effects on victims (i.e., impairment vs. intoxication/incapacitation), not simply presence or absence of alcohol use. To build on this research, we examined whether having a history of CSA or other traumatic life events related to the likelihood that (a) both the victim and perpetrator were drinking at the time of the assault, (b) only the perpetrator was drinking at the time of the assault, or (c) neither the victim nor the perpetrator were drinking at the time of the assault. We predicted that victims who reported an alcohol-related assault would be more likely to have a trauma history compared to other women. In addition, despite the fact that older women have had longer to experience traumas than younger women, we predicted that alcohol-related assaults, especially those prior to which both parties were drinking, would be more common among younger than older women because sexual assault and drinking are more prevalent and more often co-occur in younger than in older women (Bureau of Justice Statistics, 2006; Greenfield \& Rogers, 1999).

Drinking is dangerous for women because of the possibility of being assaulted while impaired or incapacitated (Kaysen, Neighbors, Martell, Fossos, \& Larimer, 2006; Krebs, Lindquist, \& Warner, 2007), but also because the contexts in which women commonly drink (e.g., bars, parties) expose them to more potential perpetrators, who are also often drinking. That is, men in these contexts may be seeking a victim to target. Alternatively, men who have been drinking may misperceive a woman's sexual interest or may simply use alcohol as an excuse for 
committing sexual assault (for review, see Abbey et al., 2001). Thus, the relationship between the victim and assault perpetrator may vary as a function of drinking. For example, Littleton and colleagues (in press) found that substance-using victims were more likely to be assaulted by acquaintances and less likely to be assaulted by romantic partners compared to non-substance using victims, although the groups did not differ in frequency of stranger assaults. Although past research has shown that perpetrators in alcohol-related assaults tend to be less well known than in assaults not involving alcohol (see Ullman, 2003 for a review), perpetrator identity has not been studied as a function of who was drinking (i.e., perpetrator, victim, or both). We predicted that perpetrators would more frequently be acquaintances or partners than strangers for assaults in which both the victim and perpetrator were drinking, but that when only the perpetrator had been drinking, he would more often be a stranger than an acquaintance or partner.

It is important to understand not only who is at risk for experiencing alcohol-related assaults and by which perpetrators, but also the effects of alcohol on specific assault characteristics. For example, past research has shown that perpetrators who drink may be disinhibited and/or feel justified to act out (Flanzer, 2005) and perpetrator-only drinking assaults result in more physical injury than those prior to which both the victim and perpetrator were drinking (Ullman \& Brecklin, 2000). Thus, we also predicted that assaults prior to which the perpetrator only was drinking would be more likely to be committed by multiple perpetrators (e.g., gang rapes), to involve more violence, and to be more severe compared to other assaults. For these reasons, we also expected victims of assaults prior to which only the perpetrator was drinking to be more likely to report perceiving that their life was in danger during the assault and to be more upset immediately following the assault compared to victims of non-alcohol-related assaults. We did not expect this when the victim was also drinking because alcohol and the 
interpersonal context of drinking together might impair or blunt victims' cognitions (Norris, Nurius, \& Dimeff, 1996).

In addition, alcohol reduces women's ability to detect risk in a situation as well as their intentions and ability to resist sexually aggressive behaviors (Testa \& Livingston, 1999; Testa, VanZile-Tamsen, Livingston, \& Buddie, 2006). Littleton and colleagues (in press) found that impaired and intoxicated victims were less likely to report verbal resistance compared to their non-impaired counterparts, although there were no differences in terms of nonverbal or physical resistance. Thus, we predicted that women who were drinking prior to their assault would report lower levels of resistance compared to victims of non-alcohol-related assaults or assaults prior to which the perpetrator only was drinking, consistent with Macy, Nurius, and Norris's (2007) finding that drinking victims reported less resistance in sexual assaults perpetrated by acquaintances than by other perpetrators. Further, we predicted that women who were drinking prior to their assaults would be less likely than other women to experience physical injury due to their lower likelihood of experiencing violent assaults (Koss, Figueredo, \& Prince, 2002; Littleton et al., in press), but more likely to experience completed rapes due to decreased resistance (Ullman, 2003).

Victims' Coping with Assault and Self-Blame

Given the variety of ways in which assaults may differ as a function of whether they are alcohol-related, victims' outcomes in terms of coping and self-blame may differ as well. Although Littleton and colleagues (in press) found no differences in victims' disengagement coping (one form of avoidance coping) in non-impaired, impaired, or intoxicated college victims, we expected more avoidance coping among victims from the community who were drinking prior to the assault than those who were not, regardless of perpetrator pre-assault drinking. This 
hypothesis is based on the notion that, compared to other women, those who are drinking before the assault may be more likely to be heavier drinkers and to have drinking problems. This is also expected because research on women in the general population shows that problem drinking is related to greater risk of avoidance coping, particularly drinking to cope with distress (Cooper, Frone, Russell, \& Mudar, 1995).

In addition, women who were drinking prior to the assault may be more likely than other women to engage in avoidance coping strategies specifically because they are more likely to blame themselves for the assault (Macy, Nurius, \& Norris, 2006; Nurius, Norris, Macy, \& Huang, 2004). That is, they may feel that had they not been impaired or intoxicated that they would have been able to avoid or resist the assault (Macy et al., 2007). This is consistent with research showing that substance use is related to self-blame in victims (Littleton et al., in press; Koss et al., 2002; Testa \& Livingston, 1999). Thus, we predicted that victims would engage in more behavioral (but not characterological) self-blame if they were drinking prior to assault compared to if they were not, regardless of perpetrator pre-assault drinking.

\section{Help-Seeking Behaviors, Social Support, and Social Reactions}

For interventions to be effective in promoting recovery in sexual assault victims, victims must first reach out for support. Thus, it is important to understand whether alcohol influences victims' help-seeking behaviors. First of all, women who were drinking prior to the assault may be more likely to withdraw from social activities and less likely to disclose the assault compared to other women because of greater feelings of self-blame and concern that others will judge and blame them for the assault. These women may also experience more negative consequences related to the assault or drinking, however, and thus may be more likely to seek social support and to disclose the assault, especially to formal support sources such as psychologists or doctors. 
In partial support, Littleton and colleagues (in press) found that impaired and intoxicated victims were significantly more likely to disclose to informal (e.g., friends, family), but not formal, support sources than were non-impaired victims.

Once victims of alcohol-related assaults disclose their experiences, what kinds of reactions do they receive? Research shows that alcohol-related assaults elicit more negative social reactions from others than do non-alcohol-related assaults (Ullman \& Filipas, 2001), but the combined effect of victim and perpetrator drinking on social reactions has not been examined. Although Littleton and colleagues (in press) did not find differences in social reactions by pre-assault drinking patterns, very few women received negative social reactions at all in that study, which the researchers attributed to greater awareness about sexual assault among college women now than in the past. Because support sources may perceive victims to be particularly blameless for assaults prior to which only the perpetrator was drinking, we expected that, in our community sample, these victims would receive more positive reactions, such as emotional supportive reactions, and fewer negative reactions, such as blaming, from others to whom they disclosed compared to victims of non-alcohol-related assaults. We also predicted that they would rate their support sources as more helpful compared to other victims. In contrast, we expected that women who were drinking prior to the assault would receive more negative reactions and fewer positive reactions compared to other women. As a result, we predicted that victims who were drinking would rate support sources as less helpful than other victims, particularly formal support providers who typically have more negative reactions to victims than do informal support providers (Golding, Siegel, Sorenson, Burnam, \& Stein, 1989; Ullman, 1996).

Psychological Symptoms 
Research has shown that victims of alcohol-related assaults, especially those involving victim drinking, report more psychological distress (Macy et al., 2006), perhaps because of their greater feelings of self-blame. Littleton and colleagues (in press), however, found no effect of alcohol involvement on assault victims' PTSD or depressive symptoms, perhaps because college women tend to be higher functioning than women in the community (e.g., Duncan, 2000). Thus, we predicted that, compared to victims of assaults that did not involve alcohol, victims of alcohol-related assaults, particularly those who were also drinking, would report more psychological symptoms of PTSD and depression. In addition, we examined the effect of alcohol on victims' post-assault problem drinking and illicit drug use, which has not been studied previously. Because victims who were drinking prior to an assault may already have more substance use problems or simply be more likely to respond to such assaults by self-medicating with substances, we predicted that victims who were drinking prior to their assaults would report more problem drinking and drug use compared to other victims.

In summary, victim, perpetrator, and assault characteristics and victim responses to assault (e.g., coping, self-blame, help-seeking, social reactions, and psychological symptoms) may all vary according to pre-assault drinking patterns of victims and perpetrators. We investigated these differences in alcohol-related assaults in a sample of women recruited from the community, who have been much less studied than college women.

\section{Methods}

\section{Participants and Procedure}

Advertisements in local newspapers and fliers distributed throughout the Chicago metropolitan area were used to invite women aged 18 or older with unwanted sexual experiences since age 14 to participate in a confidential mail survey. Interested women were mailed the 
survey along with a cover letter and information sheet describing the study, and a list of community resources for victims of violence. Women received $\$ 20$ for completing the survey and were offered a summary of the results. Of women requesting the initial survey, 1,084 returned it, a 90\% response rate, and 969 women reported having experienced sexual assault. The sample was young $(M=32$ years, $S D=11)$ and diverse $(40 \%$ Caucasian, $43 \%$ African American, 6\% Hispanic/Latina, 3\% Asian, and 8\% other). All participants were treated according to ethical guidelines of the University of Illinois at Chicago.

\section{Measures}

Alcohol-related assault. The Sexual Experiences Survey (SES; Koss \& Gidycz, 1985) was used to ensure all participants had experienced sexual assault at age 14 years or older. Women reporting multiple assaults were asked questions about their most serious assault. Women reported whether (a) both they and the perpetrator were drinking at the time of the assault ( $n=257$, or $27 \%$ ), (b) only the perpetrator was drinking at the time of the assault $(n=$ 138 , or $14 \%)$, or (c) neither they nor the perpetrator were drinking at the time of the assault $(n=$ 240 , or $25 \%$ ). We dropped from analyses 14 women who reported that they were drinking but the perpetrator was not. We also dropped 320 women who either had missing data or responded that they did not know or did not remember whether they or the perpetrator was drinking at the time of the assault. Thus, the final sample used in analyses included 635 women.

Victim, perpetrator, and assault characteristics. CSA history was measured using the Sexual Experiences Survey (SES; Koss \& Gidycz, 1985). Following Koss, Gidycz, and Wisniewski (1987), women were asked whether they had experienced completed rape, attempted rape, sexual coercion, or unwanted sexual contact before age 14 years. This variable was dichotomized (yes/no; $53 \%$ of women in our sample reported experiencing CSA). Other 
traumatic life events were assessed with Goodman, Corcoran, Turner, Yuan, and Green's (1998) Stressful Life Events Screening Questionnaire, a brief self-report measure of ten behaviorallyspecific items assessing a variety of traumatic events of an interpersonal nature (e.g., lifethreatening illness or accident, physical abuse as a child or adult). This measure has good testretest reliability (median $\kappa=.73$ ) and adequate convergent validity with a lengthier interview (median $\kappa=.64$ ). This measure was scored as the summed number of events experienced by each respondent $(M=3.06, S D=2.09)$.

We assessed women's age at the time of the assault $(M=21$ years, $S D=8)$, relationship to the perpetrator (stranger: $14 \%$; acquaintance: $47 \%$; or partner: $26 \%$ ), whether there were multiple perpetrators ( $16 \%$ said yes), and whether the perpetrator used physical violence $(60 \%$ said yes). Women reported the highest level of resistance used during the attack on a scale ranging from 0 (none) to 7 (physically fought back) $(M=4.17, S D=2.35)$ and the highest level of physical injuries sustained ranging from 0 (none) to 7 (knife/gunshot wounds) $(M=1.47, S D=$ 1.02). Based on whether women experienced unwanted sexual contact (3\%), sexual coercion (10\%), attempted rape (9\%), or completed rape $(77 \%)$, we created an assault severity scale ranging from 1 (unwanted sexual contact) to 4 (completed rape) $(M=3.61, S D=.79)$. We also assessed whether women perceived that their life was threatened during the assault $(45 \%$ said yes) and how upset they were immediately following the assault on a scale ranging from 1 (not at all) to 5 (extremely) $(M=4.14, S D=1.06)$.

Attributions of coping and self-blame. The Brief COPE (Carver, Scheier, \& Weintraub, 1989) was used to assess various strategies used in the past 30 days to cope with the assault. The self-blaming subscale was calculated based on the unweighted sum of responses, ranging from 1 (I didn't do this at all) to 4 (I did this a lot), to 2 items (e.g., "I blamed myself for the things that 
happened"). Similarly, 2 items composed the substance use coping subscale (e.g., "I used alcohol or other drugs to make myself feel better”). Avoidance coping was a sum of scores from 6 items composing the behavioral disengagement (e.g., "I gave up trying to deal with it"), denial (e.g., "I said to myself, "This isn't real"'), and self-distraction (e.g., "I turned to work/other activities to take my mind off things") subscales. The COPE has been widely used in studies of stressed populations and has adequate internal consistency reliability (all subscale $\alpha$ s $\geq .60$ except one) and test-retest reliability ( $r$ s of .46 to .86$)$. The self-blaming $(M=4.50, S D=2.03)$, substance use coping $(M=3.86, S D=2.31)$, and avoidance coping $(M=11.93, S D=4.18)$ subscales were also reliable in our sample ( $\alpha$ s $=.75, .94$, and .74 , respectively).

Two 5-item subscales of the Rape Attribution Questionnaire (Frazier, 2003), a valid and reliable self-report measure of ASA victims' attributions about why the assault occurred, assessed behavioral (e.g., "I should have resisted more") and characterological (e.g., "I am unlucky") self-blame. Each item was answered with respect to the past 30 days on a scale ranging from 1 (strongly disagree) to 5 (strongly agree). Responses were summed to calculate each subscale (behavioral self-blame: $M=17.09, S D=5.20$; characterological self-blame: $M=$ 13.27, $S D=4.57)$. Frazier $(2003)$ reported subscale alpha coefficients ranging from $.77-.89$ and test-retest reliability coefficients ranging from .68-.80 in samples of women sexual assault victims. The behavioral and characterological self-blame subscales were also reliable in our sample ( $\alpha \mathrm{s}=.83$ and .76 , respectively).

Help-seeking behaviors, social support, and social reactions. We asked women if they had ever told anyone about their assault experience. Seventy-nine percent of women had disclosed their assaults, and we asked them how many formal (e.g., medical doctor, psychologist) and informal (e.g., friend, relative) sources they disclosed to $(M=1.18, S D=1.33$, 
and $M=2.30, S D=1.08$, respectively $)$, and how helpful each type of source had been $(M=1.34$, $S D=1.10$, and $M=1.55, S D=1.10$, respectively). We also asked women whether they had ever sought counseling for distress associated with their assaults. Thirty-four percent of women had, and we asked whether they received counseling immediately (23\%), within a year of the assault $(25 \%)$, or a year or more after the assault $(52 \%)$.

Five items from the Social Activities Questionnaire (Donald \& Ware, 1984) assessed how often participants engaged in activities with their current social support networks on a scale ranging from 1 (everyday) to 7 (never or less than 5 times per year). Responses were averaged to create a reliable social support scale $(\alpha=.72 ; M=3.96, S D=1.15)$. Victims who had disclosed their assaults completed the Social Reactions Questionnaire (Ullman, 2000), reporting how often they received 48 different social reactions since the assault on a scale ranging from 0 (never) to 4 (always). Summed totals were calculated to create subscales for the total number of positive reactions (e.g., emotionally or informationally supportive reactions; $M=16.23, S D=4.13$ ) and negative reactions (e.g., blaming or stigmatizing reactions; $M=13.98, S D=7.45$ ). This measure has good test-retest reliability ( $r \mathrm{~s}=.68$ to .77 ) and evidence of several forms of validity as reported by Ullman (2000).

Psychological symptoms. The Posttraumatic Stress Diagnostic Scale (PDS; Foa, 1995) is a standardized 17-item self-report instrument used to provide a measure of PTSD symptoms using DSM-IV criteria. Women rated how often each symptom (i.e., re-experiencing/intrusion, avoidance/numbing, hyperarousal) had bothered them in relation to the assault during the past 30 days on scales ranging from 0 (not at all) to 3 (almost always). The PDS has acceptable testretest reliability $(\kappa=.74)$ for a PTSD diagnosis in assault victims over a two-week interval (Foa, 
Cashman, Jaycox, \& Perry, 1997). The measure was reliable in our sample $(\alpha=.93)$, with women reporting an average of 18.50 symptoms $(S D=12.43)$.

Depressive symptoms were assessed with the CESD-10 (Andresen, Malmgren, Carter, \& Patrick, 1994), a shortened version of the Center for Epidemiologic Studies-Depression Scale, which was developed to measure depressive symptoms in the general population (Radloff, 1977). Women rated 10 items according to how often they felt that way during the past week on scales ranging from 0 (rarely or none of the time) to 3 (most or all of the time), and responses were summed to create a total score. Cronbach's $\alpha$ for the CES-D was .85 in the general population and .90 for patients and the content, concurrent, and discriminant validity have been supported (Radloff, 1977; Weissman, Sholomskas, Pottenger, Prusoff, \& Locke, 1977). The measure was also reliable in this sample $(\alpha=.85)$. Women in our sample reported an average of $11.22(S D=$ 5.02) depressive symptoms.

The Michigan Alcoholism Screening Test (MAST; Selzer, 1971) was used to assess pastyear problem drinking. The MAST is a widely used, standardized screening instrument for alcohol abuse and dependence. We supplemented the MAST with 4 items designed to detect problem drinking specifically in women (e.g., "Has drinking had a harmful effect on your housework or chores around the house?) (Richman, 2000). The MAST has good internalconsistency reliability $(\alpha=.91)$ with a psychiatric outpatient sample (Zung, 1980), and, including the supplemental items, was a reliable measure of problem drinking in our sample $(\alpha=.81 ; M=$ $6.97, S D=10.16)$. Illicit drug use was measured by asking participants if they had used any of the following substances in the past year: psychedelics (e.g., LSD, Ecstasy), cocaine, or heroin. Forty-seven percent of women reported using one of these substances.

Results 
To determine whether our dependent variables were influenced by pre-assault drinking patterns, we conducted a series of chi-square analyses (for categorical dependent variables) and one-way analyses of variance (ANOVAs; for dependent variables). Main effects of pre-assault drinking patterns on all dependent variables are presented in Table 1. Although self-blame coping, extensiveness of women's social support networks, whether women sought counseling, and number of PTSD symptoms did not differ significantly as a function of pre-assault drinking patterns, there were many other differences between groups. We further explored these differences by conducting chi-square analyses and t-tests for all possible pairwise comparisons between women who reported that (a) both the victim and perpetrator were drinking at the time of the assault, (b) only the perpetrator was drinking at the time of the assault, or (c) neither the victim nor the perpetrator were drinking at the time of the assault. Given our a priori hypotheses, we used an alpha level of .05 for these comparisons. Results of these pairwise comparisons are presented next.

Non-Alcohol-Related Assaults vs. Alcohol-Related Assaults

Victims of alcohol-related assaults, prior to which either the perpetrator only or both the perpetrator and victim were drinking, experienced significantly more severe assaults, all $t$ s(376$495) \leq-5.38, p \mathrm{~s} \leq .001$, and sustained significantly more physical injuries, all $t \mathrm{~s}(371-484) \leq-$ $3.99, p s \leq .001$, than did victims of non-alcohol-related assaults. Compared to non-alcoholrelated assaults, alcohol-related assaults were significantly more likely to involve multiple perpetrators, all $\chi^{2} s(1,375-494) \geq 20.06, p s \leq 001$. Perpetrators of non-alcohol-related assaults were significantly more likely to be strangers than partners, $\chi^{2}(1,108)=42.82, p<.001$, but this difference was not significant for alcohol-related assaults, all $\chi^{2} \mathrm{~s}(1,59-87) \leq .56, p \mathrm{~s} \geq .45$. 
Although pre-assault drinking status did not differentiate victims in terms of frequency of seeking counseling, it did relate to timing of counseling. Victims of all types of assaults were just as likely to seek treatment immediately as they were to seek it within a year, all $\chi^{2} s(1,25-46) \leq$ $3.13, p s \geq .08$. However, victims of non-alcohol-related assaults were significantly less likely to seek counseling within one year than to delay seeking counseling for more than a year, $\chi^{2}(1,66)$ $=26.73, p<.001$. This difference did not emerge for alcohol-related assaults, all $\chi^{2} \mathrm{~s}(1,30-69) \leq$ $1.75, p s \geq .19$.

Compared to victims of non-alcohol-related assaults, victims of alcohol-related assaults received significantly more negative reactions in response to disclosures, all $t \mathrm{~s}(259-360) \leq-2.48$, $p s \leq .01$, and reported more depressive symptoms, all $t \mathrm{~s}(375-491) \leq-2.23, p \mathrm{~s} \leq .03$, and more problem-drinking symptoms, all $t \mathrm{~s}(263-399) \leq-2.15, p \mathrm{~s} \geq .03$. They did not differ, however, in use of avoidant coping following the assault compared to victims of assaults prior to which the perpetrator only was drinking, $t(354)=-1.74, p=.08$, or both the perpetrator and victim were drinking, $t(472)=1.55, p=.12$.

Non-alcohol-related assaults vs. perpetrator only drinking. Victims of assaults prior to which the perpetrator only was drinking prior to the assault used significantly more assertive resistance strategies, $t(375)=-2.70, p=.007$. Victims of assaults prior to which the perpetrator only was drinking reported significantly less behavioral self-blame than victims of non-alcoholrelated assaults, $t(373)=3.01, p=.003$. These groups did not differ, however, in terms of whether they had experienced CSA, $\chi^{2}(1,378)=1.21, p=.27$, or whether they disclosed the assault, $\chi^{2}(1,375)=.47, p=.49$. They also did not differ in characterological self-blame, $t(373)$ $=.25, p=.80$, substance use coping, $t(367)=-.92, p=.36$, or drug use, $\chi^{2}(1,369)=.33, p=.57$. 
Non-alcohol-related assaults vs. both drinking. Victims who were also drinking prior to the assault were significantly older than victims of non-alcohol-related assaults, $t(486)=-2.89, p$ $=.004$. These groups did not differ, however, in number of traumatic life experiences, $t(468)=$ $.46, p=.64$, level of resistance during the assault, $t(491)=-1.10, p=.27$, experiences of physical violence during the assault, $\chi^{2}(1,494)=.09, p=.76$, perceptions that their lives were in danger, $\chi^{2}(1,488)=.69, p=.41$, levels of post-assault upset, $t(487)=.38, p=.70$, number of formal or informal sources told, $t(396)=.49, p=.63$, and $t(398)=-.12, p=.91$, respectively, the helpfulness of either formal or informal sources, $t(220)=.28, p=.78$, and $t(382)=.46, p=.65$, respectively, or number of positive social reactions received, $t(353)=-1.12, p=.26$. Perpetrator Only Drinking vs. Other Groups

Perpetrators were significantly more likely to be acquaintances than strangers for all assault types, all $\chi^{2} s(1,71-202) \geq 4.07, p s \leq .04$, but they were also more likely to be acquaintances than partners when the perpetrator only was drinking prior to the assault, $\chi^{2}(1$, $209)=63.28, p<.001$. This difference was not significant for the other assault types, all $\chi^{2} s(1$, $76-180) \leq 1.90, p s \geq .17$.

Victims of assaults prior to which the perpetrator only was drinking reported significantly more traumatic life experiences compared to victims of non-alcohol-related assaults, $t(356)=-$ $2.30, p=.02$, or victims who were also drinking prior to the assault, $t(370)=2.63, p=.009$. As predicted, these victims were significantly more likely to experience physical violence, all $\chi^{2} \mathrm{~s}(1$, $375-393) \geq 6.11, p \leq .01$, and to perceive that their lives were in danger at the time of the assault, all $\chi^{2} \mathrm{~s}(1,373-387) \geq 36.48, p \mathrm{~s} \leq .001$, compared to other victims. They also reported significantly more post-assault upset than victims of non-alcohol-related assaults, $t(371)=-2.99$, $p=.003$, or victims who were also drinking, $t(388)=3.24, p=.001$. 
There were no differences in timing of counseling for victims of assaults prior to which the perpetrator only was drinking, $\chi^{2}(1-37) \leq 1.58, p s \geq .21$, but victims of non-alcohol-related assaults and those who were also drinking prior to the assault were significantly more likely to delay seeking counseling for more than a year than to seek counseling immediately, all $\chi^{2} \mathrm{~s}(1,57$ $67) \geq 9.28, p s \leq .002$. Victims of assaults prior to which the perpetrator only was drinking disclosed to significantly more formal and informal sources and rated those sources as significantly more helpful compared to victims of non-alcohol-related assaults, all $t$ s(176-284) $\leq$ $-2.06, p \mathrm{~s} \leq .04$, or victims who were also drinking prior to the assault, all $t \mathrm{~s}(186-314) \geq 2.26, \mathrm{ps}$ $\leq .03$. They received significantly more positive social reactions than did victims of non-alcoholrelated assaults, $t(254)=-3.30, p<.001$, or victims who were also drinking prior to the assault, $t(273)=2.89, p=.004$. They did not differ, however, in age at the time of the assault from either non-alcohol-related assault victims, $t(370)=-1.53, p=.13$, or victims who were also drinking prior to the assault, $t(384)=-.69, p=.49$.

\section{Both Drinking vs. Other Groups}

Victims of assaults prior to which both the victim and perpetrator were drinking were significantly less likely to have a history of CSA than victims of non-alcohol-related assaults or victims of assaults prior to which only the perpetrator was drinking, all $\chi^{2} \mathrm{~s}(1,395-497) \geq 14.54$, $p s \leq .001$. These victims were significantly more likely to disclose their experience than were other victims, all $\chi^{2} \mathrm{~s}(1,391-494) \geq 3.82, p \mathrm{~s} \leq .05$. They also reported significantly more behavioral and characterological self-blame, all $t \mathrm{~s}(387-491) \leq-2.39, p \mathrm{~s} \leq .02$, substance use coping, all $t \mathrm{~s}(380-483) \leq-2.31, p \mathrm{~s} \leq .02$, and illicit drug use, all $\chi^{2} \mathrm{~s}(1,384-481) \geq 9.39, p \mathrm{~s} \leq$ .002 .

\section{Differences between Alcohol-Related Assault Groups}


Victims of assaults prior to which only the perpetrator was drinking reported significantly more avoidance coping than victims who were also drinking prior to the assault, $t(374)=3.09, p$ $=.002$. The groups did not differ, however, in whether multiple perpetrators were involved, $\chi^{2}(1$, $393)=.60, p=.44$, level of victim resistance, $t(390)=1.81, p=.07$, level of injury, $t(387)=1.91$, $p=.06$, assault severity, $t(393)=1.38, p=.17$, number of negative reactions received, $t(287)=$ $1.68, p=.10$, number of depressive symptoms, $t(390)=1.53, p=.13$, or number of problem drinking symptoms, $t(300)=-.94, p=.35$.

\section{Discussion}

Researchers have documented the frequency of alcohol-related sexual assaults (Abbey et al., 2001; Ullman, 2003), yet little information exists about how characteristics and outcomes of assaults vary according to victim and perpetrator drinking prior to assault in samples of women victims in the community. Thus, in a diverse sample of community-dwelling women victims, we investigated how victim, perpetrator, and assault characteristics, coping, self-blame, help-seeking behaviors, social reactions, and mental health outcomes differed as a function of whether (a) both the victim and perpetrator were drinking at the time of the assault, (b) only the perpetrator was drinking at the time of the assault, or (c) neither the victim nor the perpetrator were drinking at the time of the assault.

Results indicated that, compared to non-alcohol-related assaults, alcohol-related assaults were more severe, more likely to involve multiple perpetrators, and resulted in more physical injuries, consistent with past research (Brecklin \& Ullman, 2002; Ullman \& Brecklin, 2000). Although these are important differences between alcohol-related assaults and non-alcoholrelated assaults, we also found differences based on a more fine-grained distinction between groups as a function of whether the perpetrator only or both the perpetrator and victim were 
drinking. Specifically, compared to all other victims, assaults prior to which the perpetrator only was drinking were characterized by more physical violence and their victims reported greater perceptions that their lives were in danger at the time of the assault and more post-assault upset, consistent with hypotheses. These findings are also in line with past research suggesting that perpetrator-only drinking assaults tend to be more serious than those involving both victim and perpetrator drinking (Brecklin \& Ullman, 2002; Ullman \& Brecklin, 2000). Further, we found that, compared to victims of non-alcohol-related assaults, victims of assaults prior to which the perpetrator only was drinking reported using more assertive resistance strategies.

Although Abbey, Ross, McDuffie, and McAuslan (1996) found that college women experienced more severe assaults when both the perpetrator and victim were drinking than if only one or neither had been drinking, women's drinking prior to assault was not associated with greater assault severity in our study of community women. Thus, at least in the present sample, the perpetrator's drinking appears to have played a greater role than the victim's drinking in affecting assault outcomes, particularly as a determinant of the level of violence in the assault.

Victims of perpetrator-only drinking-related assaults reported significantly less behavioral self-blame than victims of non-alcohol-related assaults, and disclosed to more support sources, both formal and informal, compared to women in either other group. In addition, victims of perpetrator only drinking assaults were less likely to delay seeking treatment than were other victims. The serious nature of these assaults may have led women to seek more help from a greater range of support sources. Another explanation is that perhaps women felt less stigma regarding these more stereotypical assaults, and less fear of being blamed given that they had not been drinking prior to assault, a factor typically used to hold female victims responsible (Norris \& Cubbins, 1992) and blame them (Ullman \& Filipas, 2001). In fact, these women received 
more positive reactions in response to their disclosures and rated their support sources as more helpful compared to other victims.

Also as predicted, victims who were drinking were more likely to disclose their assault than were other victims. There was no difference in the tendency to seek counseling across groups, but victims of alcohol-related assaults tended to seek counseling more immediately than victims of non-alcohol-related assaults. Again, this may be due to greater perceived assault seriousness and/or consequences for victims of alcohol-related assaults, but further research is needed to replicate this finding and to determine how help-seeking for these assaults may differ compared to non-alcohol-related assaults. Consistent with our predictions, victims of either type of alcohol-related assault received more negative reactions than did victims of non-alcoholrelated assaults. These results differ from Littleton and colleagues' (in press), who did not find differences in social reactions to victims according to victim drinking status. Their study was of college women, however, few of who received negative social reactions.

Unexpectedly, we found that women who were drinking prior to their assaults reported more characterological self-blame than did women in either other group. In support of our hypotheses and past research (e.g., Macy et al., 2006; 2007), however, compared to other women, victims who were also drinking prior to their assaults reported more behavioral selfblame, substance use coping (but not general avoidance coping), and illicit drug use. Women appear to have felt blameworthy not only for their behavior, but also for their character, when they were assaulted after drinking. Possibly as a consequence of greater self-blame (Ullman \& Filipas, 2001), victims of any alcohol-related assault reported more depression and more current problem drinking than did victims of non-alcohol-related assaults, as hypothesized. These results highlight the importance of examining unique effects of various coping strategies and other 
modifiable psychosocial factors (e.g., self-blame) to understand victims' substance use, particularly substance use coping in women whose assaults are related to problem drinking or drug use.

Victim characteristics also differed as a function of pre-assault drinking patterns. Contrary to our prediction, victims who were drinking were older at the time they were assaulted compared to victims of non-alcohol-related assaults, although all women were relatively young. In partial support of our hypothesis, compared to victims in either other group, victims of assaults prior to which the perpetrator only was drinking reported significantly more traumatic life experiences (excluding CSA). It is possible that women with trauma histories have greater difficulty detecting risk due to their greater psychological distress, and such vulnerability may lead them to be targeted by perpetrators (Gidycz, McNamara, \& Edwards, 2006).

Contrary to expectations, victims of assaults prior to which both the victim and offender were drinking were less likely to report a history of CSA than other groups in our sample, in contrast to research suggesting that prior sexual assaults are associated with alcohol-related revictimization (e.g., Gidycz et al., 2007; Testa, Livingston, VanZile-Tamsen, \& Frone, 2003). For example, Gidycz et al. (2007) found that women's risk of experiencing another assault over several months increased as a function of both level of drinking and history of and severity of prior sexual victimization. Other research has shown that alcohol use increases following alcohol-related sexual victimization (Kaysen, Neighbors, Martell, Fossos, \& Larimer, 2006), suggesting a dangerous cycle of relations between alcohol use and sexual victimization. Both of these studies examined alcohol use and sexual assault in college women, and our results may differ because we used a sample of community women and because we examined the roles of both perpetrator and victim drinking. Even in community women, however, greater problem 
drinking and alcohol dependence in sexual assault victims (Ullman et al., 2005) have been found to relate to beliefs and expectancies about how one behaves when using drugs or alcohol and drinking to cope with distress (Ullman \& Najdowski, 2009), factors that put victimized women at even greater risk of experiencing future incapacitated rape.

This study was limited by nonrepresentative sampling, retrospective design, and by the fact that victims were questioned only about details of their most serious assault. Results may have differed had we asked women to report on their most recent assault, and perhaps would have shown lower levels of assault severity and completed rape. In addition, we had no information about the amount of alcohol consumed by victim or perpetrator, and substance use information was reported only by victims, who may not have been accurate in their perceptions of perpetrator drinking. Women who were more symptomatic and had more extensive trauma histories may have been more likely to participate in this study than other victims. Missing data on alcohol use for some victims may be due to severe trauma and/or substance abuse histories, or perhaps some victims who had passed out and thus could not recall alcohol use in such assaults. Lack of response to these questions may also have resulted if women felt blameworthy due to their own drinking but feared reporting on this aspect of their assaults, knowing they might be judged for their behavior. While difficult to assess the impact of non-response to these questions on the results, it is possible that such a bias could have led to an underestimation of the effects of women's pre-assault drinking in particular. Despite these limitations, this study provides novel insight into how alcohol-involved assaults may have different correlates and consequences depending on the specific combination of victim and perpetrator drinking, and goes beyond research that has examined only whether there was any drinking or not. Further, results from our community sample clearly differ from results of studies using college samples (e.g., Littleton et 
al., in press), suggesting that further study of this important assault-related factor should be conducted using representative samples. The findings extend beyond past research by examining differences in the roles of trauma history and assault aftermath between different pre-assault drinking subgroups, not just at assault characteristics and injury outcomes (Ullman, 2003). Although only a descriptive exploratory study, the results suggest that future research should examine these issues in representative community samples to replicate these findings. Further, our results imply that we should consider both victim and/or perpetrator drinking when designing strategies for preventing sexual assault and treating victims. 


\section{References}

Abbey, A., Ross, L. T., McDuffie, D., \& McAuslan, P. (1996). Alcohol and dating risk factors for sexual assault among college women. Psychology of Women Quarterly, 20, 147-169.

Abbey, A., Zawacki, T., Buck, P. O., Clinton, A. M., \& McAuslan, P. (2001). Alcohol and sexual assault. Alcohol Research \& Health, 25, 43-51.

Acierno, R., Resnick, H., Kilpatrick, D. G., Saunders, B., \& Best, C. L. (1999). Risk factors for rape, physical assault, and posttraumatic stress disorder in women: Examination of differential multivariate relationships. Journal of Anxiety Disorders, 13, 541-563.

Andresen, E.M., Malmgren, J.A, Carter, W.B., \& Patrick, D.L. (1994). Screening for depression in well older adults: Evaluation of a short form of the CES-D. American Journal of Preventive Medicine, 10, 77-84.

Brecklin, L.R., \& Ullman, S.E. (2002). The roles of victim and offender alcohol use in sexual assaults: Results from the National Violence Against Women Survey. Journal of Studies on Alcohol, 63, 57-63.

Bureau of Justice Statistics (2006). A National Crime Victimization Survey, 2006: Statistical tables. Washington, D.C.: U.S. Department of Justice, Office of Justice Programs.

Carver, C.S., Scheier, M.F., \& Weintraub, J.K. (1989). Assessing coping strategies: A theoretically based approach. Journal of Personality and Social Psychology, 56, 267-283.

Cooper, M.L., Frone, M.R., Russell, M., \& Mudar, P. (1995). Drinking to regulate positive and negative emotions: A motivational model of alcohol use. Journal of Personality and Social Psychology, 69, 990-1005.

Donald, C.A., \& Ware, J.E. (1984). The measurement of social support. Research in Community and Mental Health, 4, 325-370. 
Duncan, R. (2000). Childhood maltreatment and college drop-out rates. Journal of Interpersonal Violence, 15, 987-995.

Flanzer, J. P. (2005). Alcohol and other drugs are key causal agents of violence. In Loseke, D. R., Gelles, R. J., \& Cavanaugh, M. M. (Eds.). Current controversies on family violence. (pp. 163-175). Newbury Park, CA: Sage.

Foa, E.B. (1995). Posttraumatic Stress Diagnostic Scale Manual. Minneapolis, MN: National Computer Systems, Inc.

Foa, E.B., Cashman, L., Jaycox, L., \& Perry, K. (1997). The validation of a self-report measure of PTSD: The Posttraumatic Stress Diagnostic Scale. Psychological Assessment, 9, 445451.

Frazier, P.A. (2003). Perceived control and distress following sexual assault: A longitudinal test of a new model. Journal of Personality and Social Psychology, 84,1257-1269.

Gidycz, C. A., McNamara, J. R., \& Edwards, K. M. (2006). Women’s risk perception and sexual victimization: A review of the literature. Aggression and Violent Behavior, 11, 441-456.

Golding, J.M., Siegel, J.M., Sorenson, S.B., Burnam, M.A., \& Stein, J.A. (1989). Social support sources following sexual assault. Journal of Community Psychology, 17, 92-107.

Goodman, L.A., Corcoran, C., Turner, K., Yuan, N., \& Green, B.L. (1998). Assessing traumatic event exposure: General issues and preliminary findings for the Stressful Life Events Screening Questionnaire. Journal of Traumatic Stress, 11, 521-542.

Greenfield, T.K., \& Rogers, J.D. (1999). Who drinks most of the alcohol in the U.S.: The policy implications. Journal of Studies on Alcohol, 60, 78-89.

Gidycz, C. A., Loh, C., Lobo, T., Rich, C., Lynn, S. J., \& Pashdag, J. (2007). Reciprocal relationships among alcohol use, risk perception, and sexual victimization: A prospective 
analysis. Journal of American College Health, 56, 5-14.

Kaysen, D., Neighbors, C., Martell, J., Fossos, N., \& Larimer, M. E. (2006). Incapacitated rape and alcohol use: A prospective analysis. Addictive Behaviors, 31, 1820-1832.

Koss, M. P., Figueredo, A. J., \& Prince, R. J. (2002). Cognitive mediation of rape's mental, physical, and social health impact: Tests of four models in cross-sectional data. Journal of Consulting and Clinical Psychology, 70, 926-941.

Koss, M. P., \& Gidycz, C. A. (1985). The Sexual Experiences Survey: Reliability and validity. Journal of Consulting and Clinical Psychology, 53, 442-443.

Koss, M. P., Gidycz, C. A., \& Wisniewski, N. (1987). The scope of rape: Incidence and prevalence of sexual aggression and victimization in a national sample of higher education students. Journal of Consulting and Clinical Psychology, 55, 162-170.

Krebs, C. P., Lindquist, C. H., \& Warner, T. D. (2007). The Campus Sexual Assault (CSA) Study. Washington, DC: U. S. Department of Justice.

Littleton, H., Grills-Taquechel, A., \& Axsom, D. (in press) Impaired and incapacitated rape victims: Assault characteristics and post-assault experiences. Violence and Victims.

Macy, R., Nurius, P., \& Norris, J. (2006). Responding in their best interests: Contextualizing women's coping with acquaintance sexual assault. Violence Against Women, 12, 478500.

Macy, R., Nurius, P., \& Norris, J. (2007). Latent profiles among sexual assault survivors: Understanding survivors and their assault experiences. Journal of Interpersonal Violence, $22,520-542$. 
Norris, J., \& Cubbins, L. (1992). Dating, drinking, and rape: Effects of victim's and assailant's alcohol consumption on judgments of their behavior and traits. Psychology of Women Quarterly, 16, 179-191.

Norris, J., Nurius, P. S., \& Dimeff, L. A. (1996). Through her eyes: Factors affecting women's perception of and resistance to acquaintance sexual aggression threat. Psychology of Women Quarterly, 20, 123-145.

Nurius, P., Norris, J., Macy, R., \& Huang, B. (2004). Women's situational coping with acquaintance sexual assault: Applying an appraisal-based model. Violence Against Women, 10, 450-478.

Radloff, L.S. (1977). The CES-D Scale: A self-report depression scale for research in the general population. Applied Psychological Measurement, 1, 385-401.

Randolph, M. E., \& Mosack, K. E. (2006). Factors mediating the effects of childhood sexual abuse on risky sexual behavior among college women. Journal of Psychology \& Human Sexuality, 18, 23-41.

Richman, J.A. (2000, December). Personal communication.

Selzer, M. (1971). The Michigan Alcoholism Screening Test: The quest for a new diagnostic instrument. American Journal of Psychiatry, 127, 1653-1658.

Testa, M., \& Livingston, J. A. (1999). Qualitative analysis of women's experiences of sexual aggression. Psychology of Women Quarterly, 23, 573-589.

Testa, M., \& Livingston, J. A. (in press). Alcohol and women's vulnerability to sexual victimization: Can reducing women's drinking prevent sexual assault? Substance Use and Misuse.

Testa, M., Livingston, J. A., VanZile-Tamsen, C., \& Frone, M. R. (2003). The role of women's 
substance use in vulnerability to forcible and incapacitated rape. Journal of Studies on Alcohol, 64, 756-764.

Testa, M., VanZile-Tamsen, C., Livingston, J. A., \& Buddie, A. M. (2006). The role of women's alcohol consumption in managing sexual intimacy and sexual safety motives. Journal of Studies on Alcohol, 67, 665-674.

Ullman, S. E. (1996). Do social reactions to sexual assault victims vary by support provider? Violence and Victims, 11, 143-156.

Ullman, S.E. (2000). Psychometric characteristics of the Social Reactions Questionnaire: A measure of reactions to sexual assault victims. Psychology of Women Quarterly, 24, 169183.

Ullman, S.E. (2003). A critical review of field studies on the link of alcohol and adult sexual assault in women. Aggression and Violent Behavior: A Review Journal, 8, 471-486.

Ullman, S.E., \& Brecklin, L.R. (2000). Alcohol and adult sexual assault in a national sample of women. Journal of Substance Abuse, 11, 405-420.

Ullman, S.E., \& Filipas, H.H. (2001). Correlates of formal and informal support seeking insexual assault victims. Journal of Interpersonal Violence, 16, 1028-1047.

Ullman, S.E., Filipas, H.H., Townsend, S.M., \& Starzynski, L. (2005). Trauma exposure, PTSD, and problem drinking among sexual assault survivors. Journal of Studies on Alcohol, 66, 610-619.

Ullman, S. E., \& Najdowski, C. J. (2009). Revictimization as a moderator of psychosocial risk factors for problem drinking in female sexual assault survivors. Journal of Studies on Alcohol and Drugs, 70, 41-49. 
Weissman, Sholomskas, Pottenger, Prusoff, \& Locke, (1977). Assessing depressive symptoms in five psychiatric populations: A validation study. American Journal of Epidemiology, 106, 203-214.

Wilsnack, S. C., Wilsnack, R. W., Kristjanson, A. F., Vogeltanz-Holm, N. D., \& Harris, T. R. (2004). Child sexual abuse and alcohol use among women: Setting the stage for risky sexual behavior. In L. J. Koenig, L. S. Doll, A. O’Leary, \& W. Pequegnat (Eds.), From child sexual abuse to adult sexual risk: Trauma, revictimization, and intervention (pp. 181-200). Washington, DC: American Psychological Association.

Zung, B.J. (1980). Factor structure of the Michigan Alcoholism Screening Test (MAST) in a psychiatric outpatient population. Journal of Clinical Psychology, 36, 1024-1030. 
Table 1

Main Effects of Pre-Assault Drinking Patterns

\begin{tabular}{|c|c|c|c|c|c|c|}
\hline \multirow[b]{2}{*}{ Categorical Measures } & Not Alcohol Related & Perpetrator Only Drinking & Both Drinking & \multirow[b]{2}{*}{$\chi^{2}$} & \multirow[b]{2}{*}{$d f$} & \multirow[b]{2}{*}{$p$} \\
\hline & \multicolumn{3}{|c|}{ Frequency } & & & \\
\hline \multicolumn{7}{|c|}{ Victim, Perpetrator, and Assault Characteristics } \\
\hline CSA history & $59 \%$ a & $65 \% \mathrm{~b}$ & $42 \%_{\mathrm{ab}}$ & 23.83 & 2,635 & $<.001$ \\
\hline Victim-offender relationship* & & & & 44.98 & 4,552 & $<.001$ \\
\hline Stranger & $10 \%$ & $26 \%$ & $16 \%$ & & & \\
\hline Acquaintance & $46 \%$ & $43 \%$ & $65 \%$ & & & \\
\hline Partner & $44 \%$ & $31 \%$ & $19 \%$ & & & \\
\hline Multiple perpetrators & $7 \%$ ab & $24 \% \mathrm{a}$ & $21 \% \mathrm{~b}$ & 25.89 & 2,631 & $<.001$ \\
\hline Perpetrator used physical violence & $58 \%$ a & $71 \%$ ab & $57 \%$ b & 8.27 & 2,631 & .02 \\
\hline Perceived life threat & $30 \%$ a & $65 \%$ ab & $34 \%$ b & 51.29 & 2,624 & $<.001$ \\
\hline \multicolumn{7}{|c|}{ Help-Seeking Behaviors, Social Support, and Social Reactions } \\
\hline Disclosure & $77 \% \mathrm{a}$ & $74 \% \mathrm{~b}$ & $84 \%$ ab & 6.56 & 2,630 & .04 \\
\hline Sought Counseling & $34 \%$ & $36 \%$ & $34 \%$ & .22 & 2,623 & .90 \\
\hline Timing of counseling* & & & & 19.62 & 4,214 & $<.001$ \\
\hline Immediately & $17 \%$ & $39 \%$ & $20 \%$ & & & \\
\hline Within a year & $15 \%$ & $25 \%$ & $34 \%$ & & & \\
\hline After a year & $68 \%$ & $37 \%$ & $47 \%$ & & & \\
\hline \multicolumn{7}{|l|}{ Psychological Symptoms } \\
\hline Illicit drug use & $40 \% \mathrm{a}$ & $43 \% \mathrm{~b}$ & $60 \%$ ab & 20.01 & 2,617 & $<.001$ \\
\hline
\end{tabular}




\begin{tabular}{|c|c|c|c|c|c|c|c|c|c|}
\hline \multirow[b]{2}{*}{ Continuous Measures } & \multicolumn{2}{|c|}{ Not Alcohol Related } & \multicolumn{2}{|c|}{ Perpetrator Only Drinking } & \multicolumn{2}{|c|}{ Both Drinking } & \multirow[b]{2}{*}{$F$} & \multirow[b]{2}{*}{$d f$} & \multirow[b]{2}{*}{$p$} \\
\hline & $M \mathrm{~s}$ & $S D$ s & $M \mathrm{~s}$ & $S D s$ & $M \mathrm{~s}$ & $S D$ s & & & \\
\hline \multicolumn{10}{|c|}{ Victim, Perpetrator, and Assault Characteristics } \\
\hline Other traumatic life events & $2.98 \mathrm{a}$ & 1.95 & $3.51_{\mathrm{ab}}$ & 2.32 & $2.89 \mathrm{~b}$ & 2.05 & 3.99 & 2,597 & .02 \\
\hline Victims' age at time of assault & $18.91_{\mathrm{a}}$ & 8.10 & $20.31_{b}$ & 9.10 & $20.88 \mathrm{a}$ & 6.96 & 3.93 & 2,620 & .02 \\
\hline Victim resistance & $3.92_{\mathrm{a}}$ & 2.38 & $4.60_{\mathrm{a}}$ & 2.29 & $4.16_{b}$ & 2.33 & 3.66 & 2,628 & .03 \\
\hline Physical injury & $1.20 \mathrm{ab}$ & 1.05 & $1.76 \mathrm{a}$ & .91 & $1.57 \mathrm{~b}$ & .99 & 15.91 & 2,621 & $<.001$ \\
\hline Assault severity & $3.34 \mathrm{ab}$ & .98 & $3.83 \mathrm{a}$ & .50 & $3.74 b$ & .64 & 23.97 & 2,632 & $<.001$ \\
\hline Post-assault upset & $4.08_{\mathrm{a}}$ & 1.04 & $4.41_{\mathrm{ab}}$ & 1.00 & $4.04_{b}$ & 1.10 & 5.90 & 2,623 & .003 \\
\hline \multicolumn{10}{|l|}{ Victims' Coping with Assault } \\
\hline Behavioral self-blame & $16.61_{\mathrm{ac}}$ & 5.43 & $14.93_{\mathrm{bc}}$ & 4.73 & $18.70_{\mathrm{ab}}$ & 4.70 & 27.01 & 2,626 & $<.001$ \\
\hline Characterological self-blame & $12.89 \mathrm{a}$ & 4.64 & $12.77_{\mathrm{b}}$ & 4.65 & $13.91_{\mathrm{ab}}$ & 4.39 & 4.13 & 2,625 & .02 \\
\hline Self-blame coping & 4.37 & 2.02 & 4.35 & 2.01 & 4.70 & 2.03 & 2.09 & 2,610 & .13 \\
\hline Avoidance coping & $12.01_{b}$ & 4.19 & $12.80_{\mathrm{a}}$ & 3.99 & $11.41_{\mathrm{a}}$ & 4.22 & 4.80 & 2,600 & .01 \\
\hline Substance use coping & $3.49 \mathrm{a}$ & 2.18 & $3.71_{b}$ & 2.26 & $4.29 \mathrm{ab}$ & 2.40 & 7.81 & 2,615 & $<.001$ \\
\hline \multicolumn{10}{|c|}{ Help-Seeking Behaviors, Social Support, and Social Reactions } \\
\hline Number of formal sources told & $1.06 \mathrm{a}$ & 1.22 & $1.80_{\mathrm{ab}}$ & 1.55 & $1.00 \mathrm{~b}$ & 1.21 & 14.60 & 2,496 & $<.001$ \\
\hline Number of formal sources who helped & $1.27 \mathrm{a}$ & 1.05 & $1.61_{\mathrm{ab}}$ & 1.11 & $1.23 \mathrm{~b}$ & 1.12 & 2.98 & 2,291 & .05 \\
\hline Number of informal sources told & $2.21_{\mathrm{a}}$ & 1.12 & $2.60_{\mathrm{ab}}$ & 1.06 & $2.22 \mathrm{~b}$ & 1.03 & 5.28 & 2,498 & .005 \\
\hline $\begin{array}{l}\text { Number of informal sources who } \\
\text { helped }\end{array}$ & $1.49 \mathrm{a}$ & 1.07 & $1.88 \mathrm{ab}$ & 1.18 & $1.44_{b}$ & 1.07 & 5.78 & 2,479 & .003 \\
\hline Social support & 4.09 & 1.23 & 3.86 & 1.12 & 3.90 & 1.08 & 2.34 & 2,611 & .10 \\
\hline Positive social reactions & $15.65 \mathrm{a}$ & 4.73 & $17.51_{\mathrm{ab}}$ & 3.29 & $16.16_{b}$ & 3.79 & 6.06 & 2,440 & .003 \\
\hline
\end{tabular}




\begin{tabular}{|c|c|c|c|c|c|c|c|c|c|}
\hline \multirow[b]{2}{*}{ Continuous Measures } & \multicolumn{2}{|c|}{ Not Alcohol Related } & \multicolumn{2}{|c|}{ Perpetrator Only Drinking } & \multicolumn{2}{|c|}{ Both Drinking } & \multirow[b]{2}{*}{$F$} & \multirow[b]{2}{*}{$d f$} & \multirow[b]{2}{*}{$p$} \\
\hline & $M \mathrm{~s}$ & $S D \mathrm{~s}$ & $M \mathrm{~s}$ & $S D s$ & $M \mathrm{~s}$ & $S D s$ & & & \\
\hline Negative social reactions & $12.14_{\mathrm{ab}}$ & 7.27 & $15.62_{\mathrm{a}}$ & 7.36 & $14.06_{b}$ & 7.42 & 7.18 & 2,453 & .001 \\
\hline \multicolumn{10}{|l|}{ Psychological Symptoms } \\
\hline PTSD symptoms & 17.93 & 12.54 & 20.51 & 12.09 & 17.95 & 12.45 & 2.32 & 2,629 & .10 \\
\hline Depressive symptoms & $10.43_{\mathrm{ab}}$ & 5.07 & $12.23_{\mathrm{a}}$ & 4.93 & $11.43 \mathrm{~b}$ & 4.91 & 6.10 & 2,628 & .002 \\
\hline Problem drinking symptoms & $4.90_{\mathrm{ab}}$ & 7.37 & $7.23_{\mathrm{a}}$ & 9.80 & $8.60_{b}$ & 11.89 & 6.79 & 2,481 & .001 \\
\hline
\end{tabular}

Note. Means with the same subscript are significantly different at $p<.05$. *See text for results of pairwise comparisons. 